\title{
Dependence of SPT Head Field Strength on Soft-Under Layer Thickness
}

T. Miyata and K. Yoshida

Kogakuin University, 1-24-2 Nishishinjuku, Shinjuku-ku, Tokyo 163-8677, Japan

We investigated the relationships between the head field strength and the time response of a single-pole-type head and the thickness of its soft under layer, using a micromagnetic simulator that takes into account the full interactions between SPT head and a double-layered medium. The results obtained showed that the head field strength is dramatically enhanced by a very thin soft under layer of $20 \mathrm{~nm}$ and that it saturates with a relatively thin layer of $60 \mathrm{~nm}$. Moreover, the delay time and the response of the head field to the exciting field increase with a thicker soft under layer.

Key words: micromagnetics, single-pole-type head, soft under layer, track width, perpendicular magnetic recording

\section{SPT ヘッド磁界強度の軟磁性下地膜厚依存性}

\author{
宮田亮・吉田和悦 \\ 工学院大学電子工学科, 東京都新宿区西新宿 1-24-2（1163-8677）
}

\section{1. はじめに}

垂直磁気記録方式の実用化が推し進められており，その 製品化も始まりつつある. 垂直磁気記録では, $200 \mathrm{~Gb} / \mathrm{in}^{2}$ 以 上の面記録密度を達成することが期待されており，将来的 には $1 \mathrm{~Tb} / \mathrm{in}^{2}$ の面記録密度も視野に入ろうとしている。こ のような高記録密度では，記録へッドである単磁極 (Single-Pole-Type；SPT)ヘッドのメインポール先端のトラ ック幅を $100 \mathrm{~nm}$ 以下とする必要がある。一方，記録媒体の 磁気異方性定数は熱摇らぎの問題を克服するため増大し続 けており，メインポールの微細化とより強い記録磁界を発 生させるという，相反する条件を満たすことが要求されて いる. 更に，線記録密度向上に伴う高速転送に対応して，記 録ヘッド磁界の素早い応答性が求められる。すでに，軟磁 性下地膜(Soft-Under Layer ; SUL)厚とメインポールの寸 法変化による磁界強度 ${ }^{1)}$ やSPTヘッドと 2 層膜媒体の各部に よる磁界応答 ${ }^{2}$, 励磁パルス, LLG方程式の制動定数による 磁界応答の研究報告がある ${ }^{3)}$. しかし，これらの報告では 検討対象が磁界強度か磁界応答のいずれかの問題に絞られ ており，両者の項目の相互関係については述べられていな い. そこで本報告では，先に開発したマイクロマグネティ ックモデルをベースとしたSPTヘッドシミュレータを用い て4), 5)，メインポールの寸法が小さくなったときの磁界強度 および磁界応答性の両者に注目し，これらの特性が媒体下 地膜の厚さやポール厚さによってどのような影響を受ける

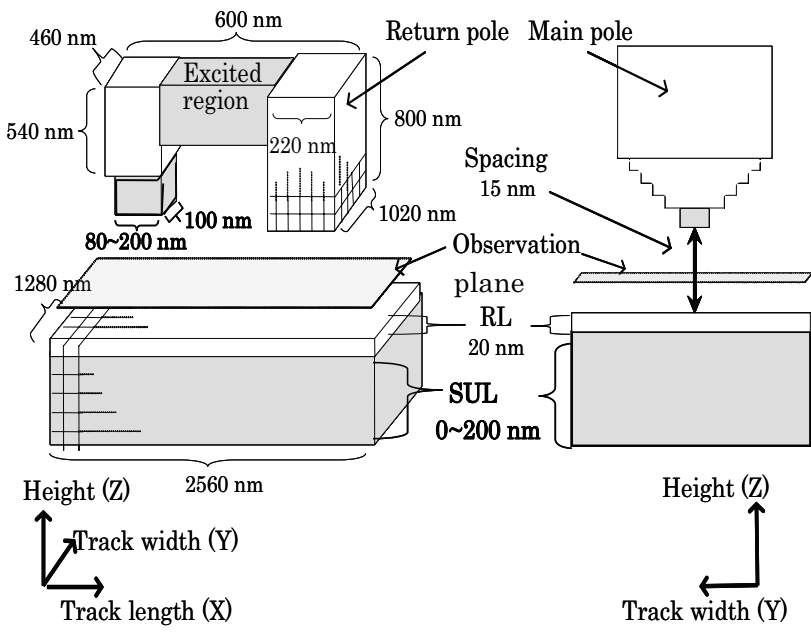

Fig. 1 Schematic model of the SPT head and double-layered medium.

か検討したものである. 本研究により，2 層膜媒体のSUL厚 が非常に薄くても，SPTヘッドの磁界を大幅に向上させる 効果があるが，厚すぎるとへッド磁界の応答性が悪くなる などの結果が得られた。

\section{2. 計算方法}

\section{1 計算モデル}

Fig.1 に計算モデルを示す. 左図はトラック幅方向から見 た鳥瞰図であり，右図はトラック方向から見た断面図とな っている. SPTヘッドと二層膜媒体を一辺 $20 \mathrm{~nm}$ の立方体 
で離散化し Landau-Lifshitz-Gilbert(LLG)方程式で磁化挙 動を計算した．磁界はヘッドと媒体の静磁気的相互作用を 厳密に計算した。メインポールからの磁界と媒体からの磁 界をメインポール先端の平面領域で平均化し足し合わせて 記録磁界とした。観察面はへッドの表面から $7.5 \mathrm{~nm}$ の位置 とした。ヘッドと媒体のスペーシングは $15 \mathrm{~nm}$ であり記録 層の中心位置 $(25 \mathrm{~nm})$ での記録磁界は，この観察面における 磁界強度と比較すると約 10\%減少することが推定された。 媒体は記録層(Recording Layer；RL)の直下部に SUL を配 置した二層膜媒体で，トラック方向 $2560 \mathrm{~nm} ，$ トラック幅 方向 $1280 \mathrm{~nm}$ とし, 膜厚は RL を $20 \mathrm{~nm}$ と一定にし, SUL を 0 200 nm の範囲で変化させた.

\section{2 計算条件}

シミュレーションに用いた SPTヘッドと RL, SUL の主 なパラメータを Table 1 に示す. SPTヘッドの磁化容易軸は トラック幅方向 Y に優先配向させた. SPTヘッドと SUL の 初期磁化方向は，それぞれ高さ-Z方向とトラック方向 $+\mathrm{X}$ と した. 実際の SPT ヘッドでは Fig.1 の Excited region にコ イルを巻き電流を流すことで励磁するが，本シミュレーシ ヨンではこの領域に一様な磁界を印加することで近似した. Fig.2 に Excited region での励磁方法を示す. 励磁磁界を $-500 \mathrm{kA} / \mathrm{m}$ から $+500 \mathrm{kA} / \mathrm{m}$ まで，立ち上がり時間 $0.4 \mathrm{~ns}$ で 直線的に変化させ, $0.4 \mathrm{~ns}$ 以降 $1.6 \mathrm{~ns}$ まで+500 kA/m を保 持した. 本条件では励磁磁界が約 $600 \mathrm{kA} / \mathrm{m}$ で記録磁界が 飽和するため，本計算条件では飽和值よりやや低い值とな っている。

本研究での計算目的は記録磁界の強度と応答性に対する メインポール厚と SUL 膜厚の依存性を調べることである. そこで Table 2 に示したように，メインポールのトラック 幅と SULの膜厚を $100 \mathrm{~nm}$ 一定とし，メインポール厚を 80 $\mathrm{nm} 200 \mathrm{~nm}$ まで変化させメインポール厚依存性を調べた. 次に，二種類のメインポール形状についてSULの膜厚を

Table 1 Calculation conditions for the SPT head and double-layered medium.

\begin{tabular}{c|ccc}
\hline Items & SPT head & RL & SUL \\
\hline Geometry & & & \\
Total length (nm) & 600 & 2560 & 2560 \\
Total width (nm) & 1020 & 1280 & 1280 \\
Total height (nm) & 800 & 20 & $0-200$ \\
Throat height (nm) & 100 & $\cdots$ & $\cdots$ \\
\hline Magnetic properties & & & \\
$K\left(\mathrm{~J} / \mathrm{m}^{3}\right)$ & $3 \times 10^{3}$ & $1.5 \times 10^{5}$ & $3 \times 10^{3}$ \\
$A(\mathrm{~J} / \mathrm{m})$ & $1 \times 10^{-11}$ & 0 & $1 \times 10^{-11}$ \\
$M_{s}\left(\mathrm{~Wb} / \mathrm{m}^{2}\right)$ & 2 & 0.6 & 1.8 \\
Exciting field $(\mathrm{kA} / \mathrm{m})$ & 500 & $\cdots$ & $\cdots$ \\
Initial magnetization & $-\mathrm{Z}$-direction & $\cdots$ & X-direction \\
Easy axis orientation & Y-direction & Z-direction & Y-direction
\end{tabular}

$K$ : Anisotropy, $A$ : Exchange constant,

$M_{S}:$ Saturation magnetization

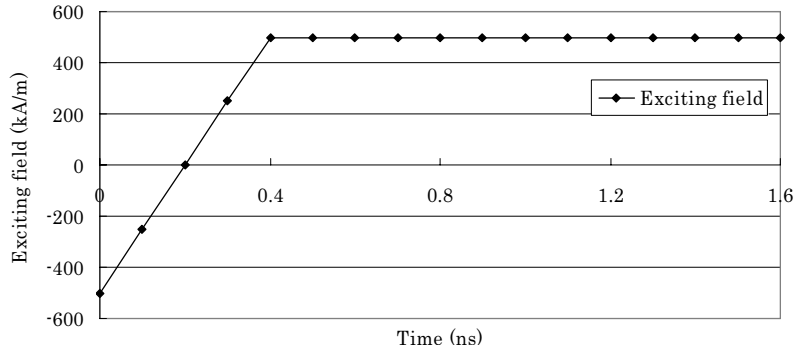

Fig. 2 Exciting field as a function of time.

Table 2 Calculation conditions for the main pole and SUL.

\begin{tabular}{c|c|c|c}
\hline \multicolumn{2}{|c|}{ Main pole } & SUL & Damping \\
$\begin{array}{c}\text { Track width } \\
\text { (nm) }\end{array}$ & $\begin{array}{c}\text { Pole thickness } \\
(\mathrm{nm})\end{array}$ & $\begin{array}{c}\text { Thickness } \\
(\mathrm{nm})\end{array}$ & $\mathrm{a}$ \\
& 80 & 100 & 0.1 \\
100 & 120 & 100 & 0.1 \\
100 & 160 & 100 & 0.1 \\
100 & 200 & 100 & 0.1 \\
100 & 160 & $0,20,60,100,200$ & 0.1 \\
\hline 100 & 100 & $20,60,100$ & 0.1 \\
60 & \multicolumn{2}{c}{} \\
\hline
\end{tabular}

0 200 nmの間で変化させSUL膜厚依存性を調べた. LLG方 程式に使う制動定数は $\alpha=0.1$, 時間刻み幅 $\Delta \mathrm{T}=1.0 \times 10^{-12}$ secとした.

\section{3. 計算結果及び考察}

\section{1 メインポール厚依存性}

Fig. 3 にメインポール厚をパラメータとして SPT ヘッド からの磁界と，二層膜媒体からの鏡像磁界を合わせた記録 磁界強度の時間経過を示す．トラック幅と SUL 膜厚は 100 $\mathrm{nm}$ 一定とし，メインポール厚を $80 \mathrm{~nm} 200 \mathrm{~nm}$ と変化さ せている. ポール厚 $80 \mathrm{~nm}(\boldsymbol{\square})$ では $1.6 \mathrm{~ns}$ 経過後の記録磁 界は $819 \mathrm{kA} / \mathrm{m}$ であるが，ポール厚 $160 \mathrm{~nm}(\triangle)$ では 916 $\mathrm{kA} / \mathrm{m}$ となりポール厚が厚くなるにつれて暫増している.

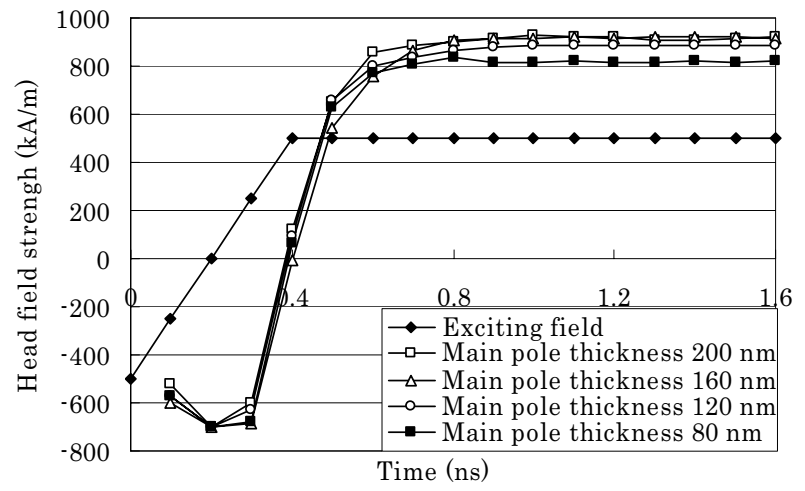

Fig. 3 Dependence of the head field on the main pole thickness for a track width of $100 \mathrm{~nm}$ and an SUL thickness of $100 \mathrm{~nm}$. 


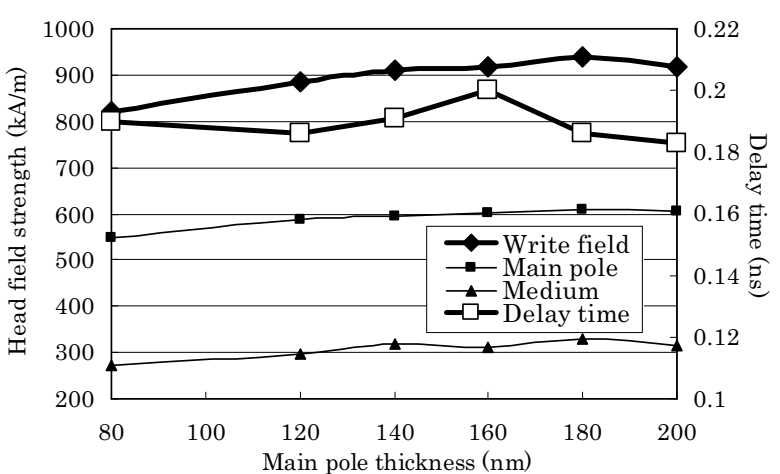

Fig. 4 Dependence of the head field and delay time on the main pole thickness for a track width of $100 \mathrm{~nm}$ and an SUL thickness of $100 \mathrm{~nm}$.

一方，励磁磁界に対するへッド磁界の応答性を，励磁磁 界と記録磁界が零をよぎる時間差を遅れ時間と定義して評 価すると，メインポール厚が変わってもへッド磁界の遅れ 時間に影響のないことがわかる.

なお記録磁界の立ち上がり時に現れる振動現象は LLG 方程式の制動定数 $\alpha$ に依存しており， $\alpha=1.0$ においてはこ の振動現象が見られないことを確認している。したがって， 初期段階に現れる振動現象は $\alpha$ が小さい場合に強調される 磁化の歳差運動と関係しているものと考えられる.

Fig.3の結果を整理すると Fig.4になる. Fig.4の記録磁界 は磁界が飽和した $1.6 \mathrm{~ns}$ 時の值でありメインポールからの 磁界と媒体からの磁界を足し合わせたものである。図中に 参考のためにメインポールからの磁界 $(\boldsymbol{\square})$ と媒体 $(\boldsymbol{\Delta})$ からの 磁界を別々に示した. Fig.4からメインポール厚を厚くする と記録磁界は緩やかに上昇する。記録磁界をメインポール と媒体からの磁界に分解すると, 媒体から得られる磁界は 記録磁界の $1 / 3$ となり，かなり大きく寄与している．また遅 れ時間はポール厚 $160 \mathrm{~nm}$ で少し増えるが全体としてポー ル厚に依存しないことがわかる．スキュー角のことを考え るとポール厚は薄いほうが好ましいため，記録磁界が 900 $\mathrm{kA} / \mathrm{m}$ とほぼ飽和するポール厚 $120 \mathrm{~nm}$ 160 nm が良いとい える.つまりポール厚はトラック幅の 1.2 倍 1.6 倍が好ま しい.

\section{2 SUL 膜厚依存性}

Fig.5 にメインポールのトラック幅 $100 \mathrm{~nm}$, ポール厚 $160 \mathrm{~nm}$ の一定条件において, SUL 膜厚を $0 \mathrm{~nm} 200 \mathrm{~nm}$ と 変化させたときの記録磁界強度の時間経過を示す. Fig.5 か ら SUL 膜がない状態 $(\boldsymbol{\Delta})$ では媒体からの相互作用が得られ ず，記録磁界は $476 \mathrm{kA} / \mathrm{m}$ と非常に弱いが，膜厚 $20 \mathrm{~nm}$ の

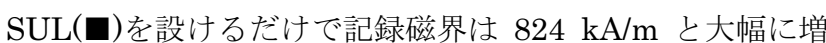
加する.さらに SUL 膜厚 $60 \mathrm{~nm}(*)$ にすると記録磁界は $940 \mathrm{kA} / \mathrm{m}$ となり, それ以上厚くしてもあまり変化しない.

一方，記録磁界の遅れ時間は SUL 膜厚が厚くなるに従

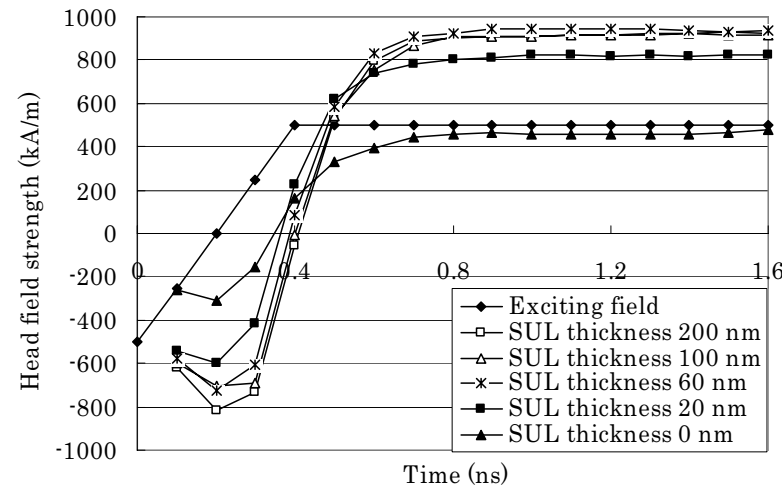

Fig. 5 Dependence of the head field on the SUL thickness for a track width of $100 \mathrm{~nm}$ and a pole thickness of $160 \mathrm{~nm}$.

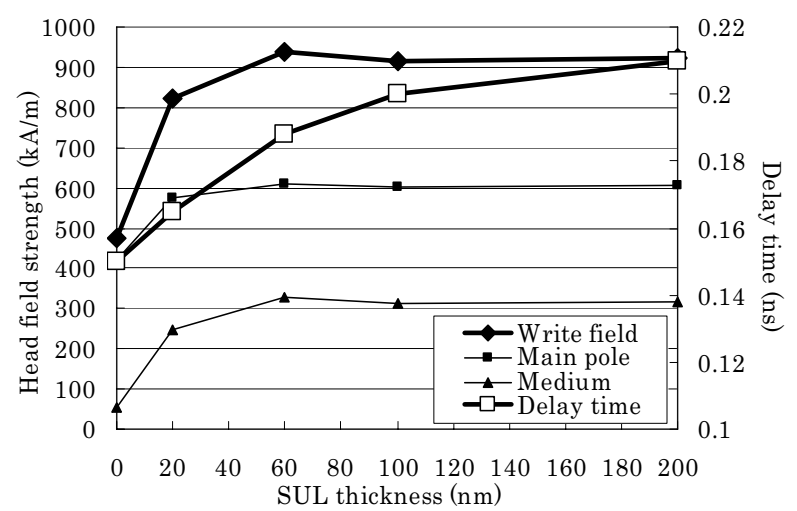

Fig. 6 Dependence of the head field and delay time on the SUL thickness for a track width of $100 \mathrm{~nm}$ and a pole thickness of $160 \mathrm{~nm}$.

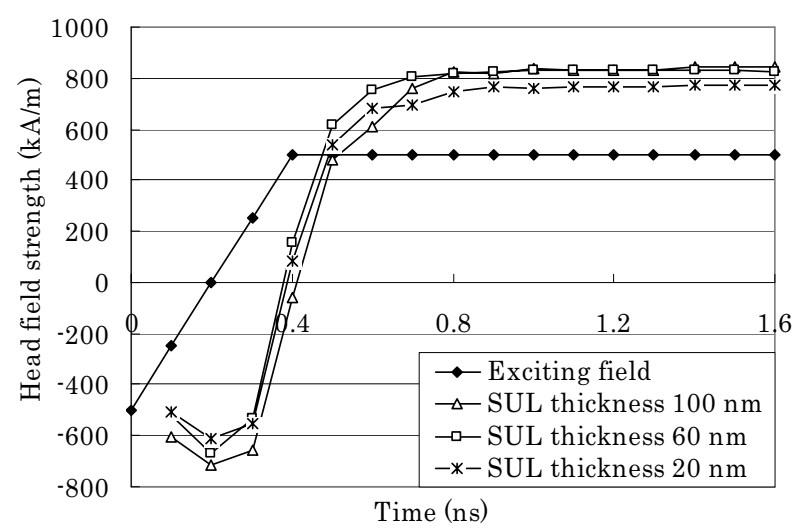

Fig. 7 Dependence of the head field on the SUL thickness for a track width of $60 \mathrm{~nm}$ and a pole thickness of $100 \mathrm{~nm}$.

い増えることから，応答性は悪くなることがわかる. Fig.6 は Fig.5の結果を整理したものである. Fig.6から SUL 膜厚 を $60 \mathrm{~nm}$ まで厚くするに従い記録磁界(け)は大きく増加す るが SUL 膜厚 $60 \mathrm{~nm}$ 以降 $200 \mathrm{~nm}$ まで厚くしても記録磁界 の大きさに変化がないことがわかる，遅れ時間( $\square)$ は SUL 膜厚が厚くなるに従い一様に増え，SUL を設けなかった時 
$0.15 \mathrm{~ns}$ であったのに対し, $200 \mathrm{~nm}$ では $0.21 \mathrm{~ns}$ と応答性は 悪くなることがわかった．以上の結果から記録磁界が飽和 し，かつ遅れ時間が $0.19 \mathrm{~ns}$ と小さな值を示す SUL の膜厚 $60 \mathrm{~nm}$ が最適であると考えられる. 以上はトラック幅が $100 \mathrm{~nm}$ の場合の結果である。

記録密度を上げるにはメインポールのトラック幅をさら に狭くする必要がある。そこで，トラック幅 $60 \mathrm{~nm}$ ，ポール 厚 $100 \mathrm{~nm}$ とした場合の SUL 膜厚依存性について調べた。

Fig.7 はメインポールのトラック幅 $60 \mathrm{~nm}$ ，ポール厚 100 $\mathrm{nm}$ の一定条件において, SUL 膜厚を $20 \mathrm{~nm} 100 \mathrm{~nm}$ と変 化させたときの記録磁界強度の時間経過を示す. SUL 膜厚 $20 \mathrm{~nm}(*)$ では記録磁界は $772 \mathrm{kA} / \mathrm{m}$ であり, SUL 膜厚の増 加とともに $60 \mathrm{~nm}(\square)$ では記録磁界 $827 \mathrm{kA} / \mathrm{m}$ と増大するが， それ以上厚くしてもほとんど変化しない. トラック幅 100 $\mathrm{nm}$ の場合と比較すると記録磁界は $12 \%$ 減少する. 遅れ時 間は先ほどと同様に SUL 膜厚が厚くなるに従い増えてお り，応答性は悪くなることが分かる．またトラック幅 100 $\mathrm{nm}$ の場合と比較しても遅れ時間に違いは見られなかった。 このように応答性がメインポールの厚さより, SUL 膜厚に 強く依存する理由として, SUL は体積が大きく必要以上の 膜厚領域では十分に磁化することができないため複雑な磁 化構造を形成し，磁界応答を妨げていると考えられる.

以上よりメインポールサイズをトラック幅 $60 \mathrm{~nm}$ ，ポー ル厚 $100 \mathrm{~nm}$ と小さくした場合でも, SUL 膜厚 $60 \mathrm{~nm}$ が最 適であると考えられる。また応答性について考えると, SPT ヘッドの磁界応答性だけでなく, SUL の応答性も考慮す心゙ き重要な要素であることが分かる.

応答性に関しては，他の研究報告では最大記録磁界の -90\% から+90\%まで変化するのに要する時間としたもの や2)，励磁磁界を印加後，最大記録磁界の+85 \%に達するま での時間としたものがある3)。そこで，後者の定義に順じた 応答性の評価を行い, 本研究結果との比較を行った.

Fig.8 にメインポールのトラック幅 $100 \mathrm{~nm}$ ，ポール厚 $160 \mathrm{~nm}(\boldsymbol{\square})$ の場合と, トラック幅 $60 \mathrm{~nm}$, ポール厚 100 $\mathrm{nm}(*)$ の場合の二種類について，上記したように定義して， SUL膜厚依存性を示した。この結果からSULが無い場合， 応答時間は $0.6 \mathrm{~ns}$ である゙SUL膜厚を $20 \mathrm{~nm}$ から $60 \mathrm{~nm}$ にすると応答が速くなり，それ以上の膜厚では応答時閒が 振動する複雑な挙動を示した。この定義で得られた応答時 間 $0.6 \mathrm{~ns}$ から $0.7 \mathrm{~ns}$ は, SUL膜厚は異なるものの, 文献值 ${ }^{2)}$ 3) とほぼ一致するものである。しかし，SUL膜厚の変化によ る振動現象は報告されていない。この原因として, SUL内 に形成される磁化分布が膜厚によって複雑に変化するため と考えられるが，今後の検討が必要である.

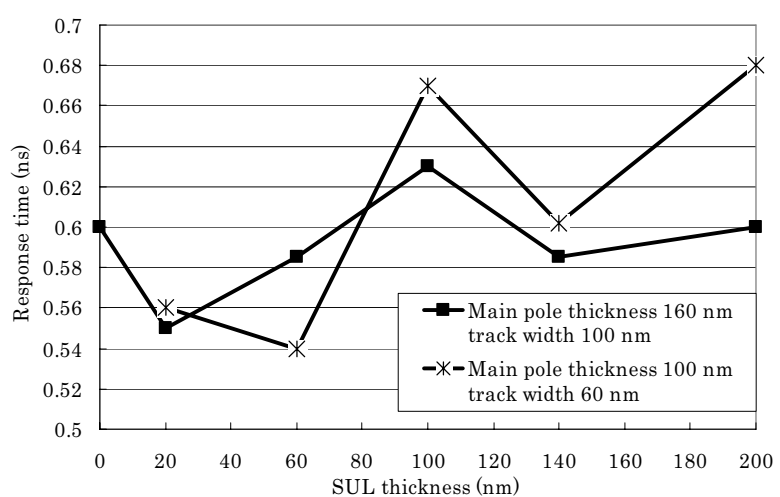

Fig. 8 Dependence of response time on SUL thickness. Response time is defined as the time until head field reaches $85 \%$ of the maximum head field.

\section{4. まとめ}

マイクロマグネティックシミュレータを用いてメインポ 一ル厚と SUL 膜厚が記録磁界強度と磁界応答性に与える 影響を調べた。その結果，本研究における計算条件におい ては，記録磁界強度はSUL膜厚 $20 \mathrm{~nm}$ と非常に薄い条件に おいても，SPT ヘッドの記録磁界を大幅に増加させる効果 をもち, $60 \mathrm{~nm}$ でほぼ飽和することが分かった。また，メイ ンポール厚はトラック幅の 1.2 倍から 1.6 倍が最適条件であ ることが分かった。

一方，磁界の応答性はポール厚にはほとんど依存せず， SUL 膜厚に依存することが分かった。これは，SUL は体積 が大きく必要以上の膜厚領域では SPTヘッドからの磁界強 度が弱くなり，磁界応答性が悪くなるためと考えられる。

謝辞 本研究の一部は情報ストレージ研究推進機構 (SRC) の支援によって行われた。ここに謝意を表します.

\section{References}

1) M. E. Schabes, B. Legsfield, and T. Schrefl, "Micromagnetic modeling of soft underlayer magnetization process and fields in perpendicular magnetic recording," IEEE Trans. on Magnetics, vol. 38, no. 4, pp. 1670-1675, July 2002.

2) K. Takano, "Micromagnetic-FEM models of a perpendicular writer and reader," IEEE Trans. Magn., vol. 41, no. 2, pp. 696 701, Feb. 2005.

3) W. Scholz and S. Batra, "Micromagnetic modeling of head field rise time for high data-rate recording," IEEE Trans. Magn., vol. 41, no. 2, pp. 702-707, Feb. 2005.

4) K. Yoshida, A. Suzuki, H. Yanagihara: J. Magn. Magn. Mater., 287, 83 (2005)

5) K. Yoshida, A. Suzuki: Technical report of IEICE., MR2004-5, p.25.

2005 年 10 月 19 日受理, 2006 年 7 月 14 日採録 